\title{
Entre psicanálise e história: o testemunho
}

\author{
Caterina Koltai* \\ Pontifícia Universidade Católica de São Paulo, Faculdade de Ciências Sociais. São Paulo, SP, Brasil
}

Resumo: Este artigo aborda a literatura de testemunho de sobreviventes de genocídios para se perguntar o que eles ensinam ao analista sobre os traumas históricos e os efeitos da violência histórica sobre a subjetividade humana. Os testemunhos são aqui entendidos como um misto de confissão, reflexão e documento histórico, e engajam a responsabilidade do analista em sua escuta tanto sobre destruição quanto sobre a resistência a ele.

Palavras-chave: trauma, testemunho, responsabilidade do analista, subjetividade, genocídio.

A questão do testemunho assumiu, devido às catástrofes históricas do século XX, uma consistência inédita, e segundo Catherine Coquio (2003) isso levou algumas testemunhas - até então não escritores - ao ato de escrever para que pudessem testemunhar a ruptura do pacto social e a humanidade destruidora de si própria. Assim como também já salientou Seligman (2000) ao precisar que a literatura de testemunho não deve ser vista como um gênero literário, e sim como a face da literatura que veio à tona nessa época de catástrofes, remetendo ao real, àquilo que resiste à representação. Confrontados ao extermínio individual e coletivo, alguns sobreviventes sentiram-se na obrigação de deixar uma marca, um traço, testemunhando a própria experiência e, apesar da maioria ter afirmado que pode-se dizer impressionantemente pouco sobre essas vivências extremas, tentaram assim mesmo tornar presente e manter atual aquilo que ali foi posto a nu, escrevendo justamente sobre esse ponto enigmático no qual foram reduzidos ao lixo do mundo, como se precisassem transmitir a verdade da realidade.

O testemunho, ao confrontar a humanidade com sua parte maldita e chamar a atenção para a posição ética que consiste transmitir o indizível, se tornou a forma privilegiada de narrar uma experiência qualificada de intransmissível justamente por aqueles que tentaram transmiti-la. Essa escrita nasceu de uma proximidade anormal com a morte, uma tentativa encontrada por alguns para integrar, ainda que minimamente, o excesso de real em jogo na experiência traumática. É o que levou, em meu entender, Levi (1987) a afirmar que escrevia aquilo que não poderia dizer a ninguém, e Elie Wiesel a responder a Jorge Semprum (Semprum \& Wiesel, 1995) em uma entrevista que se calar era proibido e falar impossível. Foi esse mesmo imperativo que fez Chalamov (1990), autor menos conhecido e que passou 16 anos em um Gulag stalinista, afirmar que sua sobrevivência só foi possível graças ao ato de escrever. Todos eles, ao escrever e testemunhar, tentaram transmitir a monstruosidade do inimaginável, a

* Endereço para correspondência: caty@osite.com.br desumanização praticada por humanos sobre outros humanos, em uma tentativa de restabelecer, por meio da escrita, seu pertencimento à espécie humana, pois como afirma Revault d'Allones (1999), toda a "literatura dos campos" de Levi a Chalamov - é habitada por uma única questão: o que é gênero humano? Pensar o testemunho, como nos diz Chiantaretto (2004), supõe pensar naquilo que funda o laço indissolúvel entre o lugar de cada um e o conjunto humano: a pertinência ao humano, razão pela qual o testemunho deve ser encarado como um ato de linguagem, uma palavra que requer a presença psíquica do outro como ser singular e representante do conjunto.

Antes de prosseguir, algumas precisões se fazem aqui necessárias. A primeira é histórica e diz respeito à época das catástrofes as quais me refiro, que é esse curto século XX, que começou um século atrás, em 1914, com a Primeira Guerra Mundial e seus oito milhões e meio de mortos na frente de batalha, cerca de 10 milhões de mortos civis e mais de seis milhões de inválidos. Logo depois, em 1915 fomos apresentados ao primeiro grande genocídio do século, o armênio de 1915, que vem sendo trabalhado há mais de uma década por Altounian (2000) em um belíssimo trabalho, para rapidamente desembocarmos na Segunda Grande Guerra que terminou com a bomba atômica lançada sobre populações civis de Hiroshima e Nagasaki. Com suas duas grandes guerras, seus dois totalitarismos e seus campos de reeducação estalinista e de extermínio nazista, não é de se admirar que o século XX seja considerado o mais trágico da história, aquele em que, como bem lembra Freud (1939/1948) em um de seus prefácios a Moisés e o monoteísmo, o progresso concluiu um pacto com a barbárie.

Freud rapidamente se deu conta da tragédia em curso, tanto que já em 1915, seis meses após o início da Primeira Grande Guerra, enquanto seus dois filhos se encontravam na frente de batalha, escreveu "Considerações sobre a guerra e a Morte" (Freud, 1915/1981a), texto em que começa falando da desilusão trazida pela guerra, continuando pela constatação de que quando os mortos são tantos que já não podem ser reconhecidos individualmente fica impossível nomear a morte e viver o luto, o 
que por sua vez não tem como não acarretar uma mudança na humanidade da ordem da transformação da linguagem. E como se ele previsse o que ainda estava por vir, se pergunta se a humanidade constituída no crime e pelo crime não estaria se dirigindo inevitavelmente para a destruição.

A guerra e as neuroses de guerra rapidamente colocaram questões aos analistas, como podemos constatar nos anais do V Congresso da Associação Psicanalítica Internacional realizado em Budapeste em 1918, na Europa recém-saída da guerra, em um momento em que o armistício sequer fora assinado. Foi ali que os psicanalistas, reunidos em torno de Freud após vários anos de separação, tentaram entender os efeitos da guerra sobre suas práticas e teorizações. As contribuições de Abraham (1973), Ferenczi (1919/1970) e outros diretamente implicados na guerra, editadas sob o nome de Psicanálise das neuroses de guerra, continuam ainda atualíssimas. Eles logo se deram conta que essas neuroses traumáticas divergiam em muitos aspectos das já conhecidas neuroses de transferência, e que entre as diferenças existia o fato de que nessas neuroses a dimensão sexual parecia ausente.

Apesar do mal-estar provocado por essa constatação, não se furtaram ao desafio de tentar entender esses novos sintomas, percebendo rapidamente que ao contrário do que acontecia nas neuroses de transferência, nas neuroses traumáticas em vez de se depararem com a já conhecida amnésia, precisavam lidar com um excesso de memória, uma vez que o problema dos traumatizados residia justamente em não poder esquecer nem a cena nem os acontecimentos dos quais foram vítimas, visto que tais acontecimentos não cessavam de assombrar a consciência e o sono dos pacientes. Na neurose traumática o vivido traumático inicial não é recalcado nem entra em ressonância com a rede simbólica que caracteriza nesse momento a posição e a estrutura do sujeito, a lembrança do trauma permanecendo presente sem modificações e sem se fragmentar em vários fantasmas.

Quanto a Freud, a necessidade de integrar as particularidades clínicas e psicopatológicas das neuroses de guerra o levou a uma reelaboração de toda sua teoria. Introduziu a pulsão de morte e um novo dualismo pulsional no qual o conflito entre Eros e Tânatos passou a atravessar tanto o processo civilizatório quanto o desenvolvimento individual. A partir de Além do princípio do prazer (Freud 1920/1981b), surgiu em Freud uma nova concepção de traumatismo que lhe permitiu opor as neuroses de transferência às neuroses traumáticas, ficando claro que aquilo que a neurose de transferência recalca, a neurose traumática torna presente - uma presença terrível que faz com que o sujeito não cesse de reviver a cena traumática, razão pela qual no lugar da angústia enquanto mecanismo de proteção contra o perigo, o afeto predominante na neurose traumática é o pavor, uma vez que o acontecimento traumatizante atinge um psiquismo não preparado, portanto mais vulnerável.

Freud não viveu o bastante para tirar todas as conclusões da Segunda Guerra Mundial, que começou em
1939 e terminou em 1945, deixando um balanço de mais de 35 milhões de mortos só na Europa. Assim como não viveu o bastante para tirar todas as conclusões sobre os campos de extermínio nazistas nos quais morreram duas de suas irmãs. Só entre judeus, ciganos e doentes mentais foram mais de 6 milhões de vítimas. Mas se ele não pôde fazê-lo, outros o fizeram em seu lugar, entre os quais gostaria de salientar Lacan (1968) e Zaltzman (1999). O primeiro por chamar nossa atenção para a mudança que representou para nossa subjetividade a passagem de um mundo organizado em torno da religião para um mundo organizado em torno da ciência, e a percepção decorrente dessa constatação, que é a de que a segregação que chegou ao extremo com os campos iria, necessariamente, se ampliar.

O segundo por ter explicitado claramente que, ao atacar a noção de espécie humana, o regime nazista demonstrou que valores que acreditávamos definitivamente inscritos na história podiam se desfazer de uma hora para outra, fazendo com que a humanidade adentrasse em um novo patamar do mal, do qual ainda somos os tristes herdeiros, uma vez que a realidade totalitária e concentracionária nos colocou perante um acontecimento maior, coletivo e individual, posterior à metapsicologia freudiana da Psicologia das Massas, o do desmoronamento da civilização ocidental em sua função de proteção do indivíduo contra o reino do assassinato, desmoronamento esse que passou a fazer parte de cada um de nós e da herança da realidade humana.

Agamben (1997) vai nessa mesma direção ao chamar nossa atenção para o fato de que a História do século $\mathrm{XX}$, por meio dos seus regimes totalitários e formas inéditas de massacre, inscreveu o assassinato de milhares de pessoas como algo possível, fora de qualquer norma, como se os humanos não participassem de uma realidade comum, a ponto de o assassinato ter deixado de ser entendido enquanto tal, como podemos constatar diariamente na longa série de genocídios em massa que se seguiram à derrocada do nazismo - entre os quais, só para citar alguns, estão o cambojano, o ruandês e os perpetrados por algumas ditaduras latino-americanas com seus estádios transformados em depósitos humanos e seus anjos da morte que atiravam pessoas vivas para fora do avião.

A segunda precisão diz respeito ao lugar do qual falo: o de uma analista cidadã que, interpelada pelos efeitos da violência da história sobre a subjetividade humana, vem se interessando pela assim chamada literatura de testemunho, sem ser ou pretender ser uma especialista dessa literatura. Entendo esses testemunhos como um misto de confissão, documento histórico e reflexão que o sujeito faz sobre si próprio e que convém encarar não como uma mera manifestação da memória, mas como uma atividade de pensamento aplicada à compreensão do inumano enquanto produção política humana. Se assim é, é porque enquanto analista me sinto no dever de escutar a História que acompanha e emoldura as histórias que escuto, o que me coloca perante a responsabilidade de poder ouvir tanto a destruição quanto a resistência a ela. 
Os testemunhos sobre os quais me debruçarei aqui são, em sua quase totalidade, testemunhos da Shoah, e remetem a um trauma que ao mesmo tempo em que interrompeu a atividade psíquica do sujeito o força incessantemente a retomar o pensamento lá onde foi interrompido. Minha escolha por esses testemunhos se deve em parte porque considero a Shoah o paradigma mor da catástrofe social e política do século XX, e em parte porque foi ela que nos legou a maior parte daquilo que passamos a chamar de literatura de testemunho. Penso, enquanto analista, que tenho muito a aprender com os escritores dos campos que escreveram e descreveram o que haviam conhecido nos campos da morte, esperando que aqueles que os lessem pudessem imaginar o inimaginável, partilhando algo com eles. Entre eles, como bem lembrou Oppenheim (2012), encontramos judeus, cristãos, ateus, resistentes, políticos, poetas amantes e adolescentes forçados a amadurecer na marra, semelhantes e profundamente diferentes daqueles que não sofreram esse terrível destino, uma vez que suas obras foram escritas em uma proximidade anormal com a morte, fato esse que os obrigou a ter que elaborar profundas transformações na relação que mantinham com o tempo, espaço e com o próprio corpo.

A figura da testemunha sobrevivente que se descortina por meio dessas leituras permite ao testemunho ultrapassar o stricto campo jurídico, reunindo assim, como nos mostra Agamben (1999), os três termos que em latim existiam para definir a testemunha: Testis, aquela que intervém como terceiro no conflito entre duas pessoas; Supertes, a que tendo vivido integralmente uma experiência, sobreviveu e pode contá-la aos outros; e Aucotor, aquela em que seu testemunho exige sempre que algo - fato, ser, palavra - $o$ anteceda, cuja realidade e força devem ser confirmadas ou certificadas. A partir dessa distinção, Chiantaretto (2004) afirma que com Primo Levi, a testemunha sobrevivente da Shoah, temos que redefinir o testemunho como sendo o ato pessoal de um sujeito alterado pela alteridade do passado do qual testemunha, pela alteridade daqueles perante os quais testemunha e que toma por testemunha.

$\mathrm{O}$ que disse até o momento me permite afirmar que a leitura da literatura de testemunho me ajuda em meu ofício de analista na medida em que entendo o testemunho como um ponto de articulação entre história pessoal e coletiva, que remete tanto à responsabilidade do sujeito que fala quanto àquela de quem o escuta. Penso, assim como Levallois (2007), que a psicanálise não pode se dar ao luxo de esquecer que lida com um sujeito histórico, depositário de uma história, razão pela qual todo analisando acaba em um determinado momento de seu percurso se vendo obrigado a testemunhar a relação que sua história individual mantém com a grande História, o que por sua vez exige a escuta de um analista capaz de relacionar a escuta da história que ouve com a História do mundo; caso contrário, em vez de ajudar seu analisando a construir sua singularidade, criará nele o sentimento ilusório e tóxico de o estar abandonando a uma solidão de exceção, e de ser o único a ter vivido determinado horror.
O testemunho, enquanto relato assumido e endereçado cuja autenticidade é atestada pela presença do narrador no acontecimento relatado, assume a partir daí duas funções distintas: a atestação dos fatos e a revelação de uma verdade, sendo que é no trajeto do real à verdade que intervém a forma literária que postula o valor de um sentido. De todos os autores citados, Levi (1989) se tornou o mais emblemático de todos na medida em que não só toda sua obra é habitada pela desumanização que viveu nos campos, como a transmissão dessa vivência se tornou o maior desafio de sua vida, já que a ofensa vivida em Auschwitz, esse lugar de destruição da metáfora onde não havia lugar para o warum, nunca acaba. Esse dever de testemunhar se reflete em seu rigoroso trabalho de escrita tanto no estilo quanto na forma e no vocabulário.

De fato, e nunca é demais repetir, Auschwitz representou o momento de uma irreversibilidade do inumano que nenhuma palavra pode expressar, visto que todo testemunho é testemunho do humano. Os que testemunharam e cujos testemunhos chegaram até nós o fizeram tanto em nome próprio quanto em nome dos que já estavam mortos antes de serem mortos, antes de desaparecerem definitivamente nas câmaras de gás. Seus restos foram privados do estatuto de cadáver e por isso mesmo não foram sepultados, apagando dessa forma a fronteira entre o vivo e o morto, uma vez que a essência do nazi-fascismo foi matar a morte, fazer reinar a morte, infectando com isso a vida.

Ler esses autores e estar à escuta daquilo que conseguiram dizer sobre a barbárie foi a maneira que encontrei, assim como Oppenheim (2012), de assumir meu lugar enquanto elo vivo do testemunho, na cadeia de transmissão que eles iniciaram, contribuindo para que suas experiências não fossem esquecidas e eles pudessem se desprender da alienação ao Campo, assumindo o lugar que lhes cabe em nossa sociedade. Minha tentativa aqui é a de passar adiante o que fui capaz de ouvir, tentando imaginar o incompreensível e acreditar no inacreditável; isso é menos óbvio do que parece, até porque o esquecimento do extermínio faz parte do extermínio.

Entendo isso como um dever ético, assim como testemunhar o foi para muitos daqueles que voltaram do inferno, encontrando na escrita uma forma de permanecerem temporariamente vivos e pagar suas "dívidas" para com os que lá ficaram. Por meio de seus testemunhos e de suas escritas, eles devolveram de certo modo a voz dos que ali ficaram emprestando palavras aos mortos, para que o humano não deixasse de ser humano e pudesse continuar a existir em relação ao conjunto dos humanos.

É por isso que entendo que a leitura dessa literatura exige do leitor, ou pelo menos exigiu de mim, algo que só depois vim a nomear, que é uma ética da leitura, postura necessária para se deixar atravessar pela escuta da complexidade daquilo que eles escreveram, uma vez que uma leitura cuidadosa desses textos permite perceber que em determinado momento o sentido reaparece no não sentido, trazendo consigo dor e prazer, e devolvendo, segundo Coquio (2003), vida e valor ao espírito e à língua, dando 
uma forma de consciência e intelectualidade ao ato de sobreviver. Essa mistura é de tal ordem que algumas testemunhas, ao sobreviverem, se tornaram e permaneceram escritores; o testemunho se transformou em literatura, independentemente do fato de terem se lançado na escrita assim que voltaram dos campos, como Levi (1987) e Antelme (1947), ou só anos mais tarde como Améry (2005), Delbo (1970) ou Semprum (1994).

A literatura concentracionária, segundo Zaltzman (1999), põe em evidência a existência de uma referência inconsciente que, em situações extremas, assume a forma consciente ou não de que cada vida representa de modo impessoal a vida humana, a condição humana em seu conjunto. Ela testemunha a existência de uma referência inconsciente de inclusão indestrutível do indivíduo no devir do humano. Esse pertencimento à espécie humana, nos termos de Antelme, parece sobreviver à destruição de todas as marcas da civilização, sendo o que Zaltzman (1998) em um livro anterior nomeou de identificação sobrevivente, no sentido mais pleno do termo e que remete àquilo que no humano resiste, não perde o rumo, não descola de sua inscrição na realidade humana, mesmo quando essa realidade tal qual ela podia ser pensada até então deixou de ser inteligível nos termos legados pela história humana. O humano não deixa de ser humano, independentemente do que lhe aconteça, e não deixa de existir em relação ao conjunto dos humanos mesmo na realidade bestial e mecânica.

É disso que nos fala Antelme (1947), jovem resistente comunista francês, que após ter sobrevivido a Buchenwald e Dachau publicou o já clássico L'Espèce humaine. Vale a pena nos determos um pouco no autor e no livro, principalmente em seu título que, a meu ver, pode ser tomado como um convite metodológico para uma nova meditação sobre o humano que não procederia mais da política, e sim da própria vida, sempre deixada de lado pelo pensamento político. Em seu livro podemos ler as verdadeiras estratégias de sobrevivência que foram postas em prática por seres confrontados a situações tão extremas que em alguns despertou uma determinação de permanecer vivo a qualquer custo, uma reivindicação quase biológica que pode servir para meditar sobre os limites da espécie e sobre certa solidão da espécie, e conceber uma opinião mais clara de sua indivisível unidade. Seu livro nos leva a refletir sobre o fato que o ser humano, como já dizia Blanchot (1996), ainda que indestrutível pode ser destruído. É em todo caso o que leio em suas palavras quando afirma que "não há ambiguidade, permanecemos sendo humanos e acabaremos enquanto tais. . . é por sermos humanos como eles que os SS acabarão impotentes perante nós . . o carrasco pode matar um homem mas não pode transformá-lo em outra coisa" (Blanchot, 1996, pp. 77-87). Mas bem que os nazistas tentaram de todas as formas, inclusive reciclando partes do corpo de suas vítimas.

É nesse ponto que me pergunto até onde o humano pode ir para sobreviver sem perder sua humanidade constitutiva, já que a vida não passa de um tênue fio que pode se romper a qualquer momento. $\mathrm{O}$ que faz com que o fio não se rompa? Encontrei a resposta a essa pergunta esparsa em vários desses autores, entre eles o próprio Antelme (1947), Levi (1987), Bubber Newmann (1986), Delbo (1970), Stewart (2009) e Semprum (1994, 1995). Não vou aprofundar aqui esse tema, até porque já o fiz em outro artigo (Koltai, 2011), mas não posso me furtar a chamar atenção para o fato de que nessas situações extremas, quando se é submetido a tratamentos desumanos, algo pode colaborar para manter o fio da vida: a relação de amizade que se tece entre aqueles que estão submetidos ao mesmo destino e lutam pela vida lado a lado. Em minha viagem por essa literatura me dei conta de que todos os sobreviventes evocam os grupos aos quais pertenceram, reconhecendo que era deles que vinha a ajuda indispensável para sobreviver, tanto a ajuda concreta de uma concha de sopa, de um gole de água ou de um ombro amigo que evitava a queda, quanto a moral na forma de um sorriso, de uma palavra ou de um olhar.

A palavra grega philia assume aqui toda sua grandeza e remete ao laço incondicional que os sobreviventes de catástrofes gostam de rememorar entre si, e até de transmitir, na maioria das vezes pulando uma geração. Essas relações podem ser tão intensas que fica até difícil encontrar o termo exato em qualquer outra língua, uma vez que é mais outra coisa que a amizade ou o amor, é um sentimento tecido nesse campo do Real, do qual dificilmente nos aproximamos em tempos normais.

Para ilustrar o que estou querendo dizer me remeto novamente a Antelme, que ao retornar de Dachau manteve uma importante correspondência com seu amigo Dionys Mascolo, na qual podemos acompanhar o (re)nascimento de um ser que aos poucos vai voltando à vida, justamente graças à presença amiga de Mascolo, que funcionou como outro garantidor da alteridade. Mascolo assumiu para Antelme a função de testemunha do testemunho, função que Waintrater (2005) descreve como "intermediária e provisória, mas indispensável e que se produz no encontro do corpo próprio de Antelme e o eu do outro." (p. 103). Sempre segundo ela, Mascolo, em sua função de testemunha da testemunha, esteve totalmente investido de uma função "empática materna", como é possível constatar nas palavras que Antelme lhe escreveu: "E a você que eu escrevo em primeiro lugar, pois quero que possa entreter em você . . . o maravilhoso sentimento de ter salvado um homem" (Waintrater, 2005, p. 103). Não por acaso, Waintrater afirma que encontramos nessas palavras de Antelme as marcas da gratidão, já que o salvado guarda eternamente a imagem do salvador, gratidão que se aparenta ao sentimento amoroso, incrível intimidade entre dois seres ligados para sempre. Será que não podemos dizer que a presença amiga de Mascolo funcionou nesse momento como uma função analítica que pode ouvir sem julgar e sustentar a palavra do amigo permitindo-lhe voltar à vida? Creio que sim.

Em A trégua de Primo Levi (1997) o pequeno Urbinek é descrito como: 
um nada, um filho da morte, um filho de Aushchwitz . . . não sabia falar e não tinha nome . . . aquele curioso nome Urbinek fora-lhe dado por nós. . . . As palavras que lhe faltavam ... a necessidade da palavra, tudo isso comprimia seu olhar com urgência explosiva. (pp. 28-29)

Esse desejo de palavra ocorreu de fato por Heneke, que passou os dias anteriores à morte de Urbinek a seu lado; podemos pensar que foi sua presença amiga que possibilitou ao menino pronunciar uma palavra que, embora incompreensível, todos se esforçaram em decifrar. Faço a hipótese que foram os cuidados dispensados por Heneke que permitiram a Urbinek entrar na linguagem, razão pela qual ouso afirmar que a presença de Heneke ao lado de Urbinek correspondeu a algo da ordem de uma presença analítica.

No livro de Bubber Newmann (1986), jovem comunista alemã que se refugiou na URSS e acabou sendo entregue por Stalin à Gestapo, lemos algo que também me parece ir na mesma direção. Ela foi internada no campo de Ravensbruck, onde conheceu Milena Jesenská (a famosa Milena de Kafka). Entre elas se desenvolveu uma sólida amizade descrita nos seguintes termos: "Milena sabia fazer falar, contar, lembrar, consolar e partilhar a dor do outro. . . Milena soube me ajudar a me curar, ela encontrou o caminho do meu coração" (Newmann, 1986, p. 20). E mais adiante:

Uma amizade é sempre um presente, um grande prêmio .... Enquanto pudemos permanecer juntas, Milena e eu conseguimos suportar tudo aquilo que o presente tinha de insuportável . . . essa amizade se tornou um protesto aberto contra a desumanização que sofríamos. (p. 24)

Esse lugar da philia nas catástrofes históricas e a função analítica que o amigo pode desempenhar em tais situações tem sido abordada por vários autores, entre os quais gostaria de destacar a importante obra de Davoine e Gaudillère (2006), que em um livro escrito a quatro mãos, Histoire et trauma, defendem a ideia de que o trauma reduz o indivíduo a uma interioridade invadida pela angústia do nada, e que o sujeito ao se tornar coisa entre as coisas se vê condenado à solidão, a uma ruptura absoluta de todos os laços comunitários e culturais, sendo que nada na cultura contemporânea se oferece para ajudar a reintegrar a vítima ao mundo dos vivos, a não ser - de certa maneira - a psicanálise, que tenta encontrar o ponto de ruptura de um antes, no qual fantasma e sonho ainda tinham seu lugar.

Se uma das saídas do traumatismo é a adesão a ideologias que tem por palavra de ordem a erradicação da memória, é importante notar que os sintomas traumáticos são - como já foi apontado no início deste artigo - o sinal de uma memória por demais presente. Nessas situações, me parece que o lugar transferencial do analista não pode ser o mesmo que ele ocupa nas neuroses de transferência, pois uma proximidade maior se torna necessária ao mesmo tempo em que o analista precisa agir com o máximo de tato. Eis aí um significante polêmico e polissêmico que remete tanto ao tocar quanto ao que é ou não conveniente, o que mantém o sentido da medida, a discrição e a cadência musical ou ao efeito produzido no espírito principalmente pela música e pela poesia, e na polêmica às divergências entre Freud e Ferenczi, razão pela qual ele merece que nos atenhamos um instante a ele.

$\mathrm{O}$ tato era algo que ambos julgavam importante, ainda que não entendessem exatamente a mesma coisa ao se referirem a ele. Enquanto Freud relacionou o tato a tudo aquilo que não deveria ser feito em uma análise, alertando seus discípulos para as tentações que deveriam evitar, Ferenczi (1928/2003) abordou a questão positivamente, principalmente em seu célebre texto de 1928, "A elasticidade da técnica psicanalítica", no qual afirma que o timing do analista no que diz respeito a saber quando se julga de posse de um material suficiente que possa ser comunicado ao paciente, é uma questão de tato, definido como a faculdade de "sentir com", o paciente bem entendido. Dito de outro modo, ele nos aconselhou a evitar a interpretose julgando o analisando capaz de realizar grande parte desse trabalho sozinho, com a condição de sentir a presença do analista ao seu lado.

Sentir com é da mesma ordem que a exigência moral de não fazer ao outro aquilo que em circunstâncias análogas não gostaríamos que os outros nos fizessem. Como salienta Kezem (2010), tal afirmação não tem nada de moralista, é uma mera consequência de sua compreensão do ambiente traumatogênico do ambiente, valendo para o próprio setting analítico, sendo que o analista deve estar atento ao papel que viria a exercer para o paciente: facilitador ou traumatogênico. Ao recomendar paciência e tolerância aos analistas, certamente não estava recomendando que eles cedessem aos caprichos do analisando, apenas que deveriam se afinar com eles, no sentido de se colocar no mesmo diapasão que os pacientes, no entanto sem sair da posição de analista. Não por acaso, destacou-se como o analista dos casos graves, assim como creio que também não foi por acaso que se interessou pela questão da amizade, como bem lembrou Prado de Oliveira (2012).

$\mathrm{O}$ interesse de Ferenczi pela amizade vale que nos detenhamos rapidamente nela, uma vez que é um termo que ele utilizou em inúmeras ocasiões para salientar a importância do afeto na promoção das trocas pessoais. Ao longo de sua obra nos deparamos com várias referências à amizade, entendida como um afeto que pode ser experimentado pelo analista com o analisando, como na conferência que deu em 1930, em Madri, na qual defendeu explicitamente a importância de "uma amizade tácita" entre analista e analisando que sirva de suporte ao processo analítico. Como salienta Prado, o sentido implicado no afeto amizade por Ferenczi aponta para a necessidade de colocar em pauta a questão na amizade envolvida na transferência.

Fechado esse pequeno parênteses ferencziano que, no entanto, me pareceu necessário para a continuação do 
trabalho, volto aos sintomas traumáticos e ao que dizia a respeito da posição do analista na análise de certos pacientes que exigem dele uma proximidade maior do que a recomendada nas neuroses de transferência. $\mathrm{E}$ isso por inúmeras razões, entre as quais a de que a vergonha parece ser o afeto mais comum encontrado nas neuroses traumáticas em oposição à angústia e à culpa que caracterizam as neuroses de transferência. Como salienta Piret (2013) a partir de sua longa experiência com sujeitos traumatizados, a vergonha não remete à cena sexual edípica e sim a um estágio de constituição do sujeito anterior, o da formação do eu no olhar do Outro. Tratar-se ia aqui, segundo ele, de fazer face ao que Agamben (1997) chamou de "vida nua", que é uma destruição do sentimento de humanidade no humano e que remete a uma existência quase biológica, desatada das filiações simbólicas que são próprias do humano. Diante do humano traumatizado que se sente abandonado, não apenas por seu grupo de pertencimento, mas pela humanidade como um todo, já não tendo mais o registro do que significa interessar alguém, o analista não pode repetir o crime e se contentar "em permanecer identificado ao modelo caricatural do espelho sem reação, da neutralidade absoluta e do silêncio glacial que alguns acreditam de praxe" (Agamben, 1997, p. 173). Nesses casos, não só ele pode, mas deve manifestar sua curiosidade e seu investimento explícito na escuta que suscitou nele um desejo de saber. Em outros termos, dessa vez lacanianos, o analista não pode hesitar em manifestar seu desejo, seu desejo de analista.

Encaminhando-me para a conclusão, retomo aqui o que julgo ser a responsabilidade do analista, que a meu ver reside na necessidade e capacidade de ouvir a grande História que acompanha a história do sujeito, assim como a transmissão transgeracional, no sentido de que todo genocídio é a destruição simultânea de três gerações, as mesmas que são necessárias para o estabelecimento de qualquer filiação. Depois de um genocídio o sujeito deixa de ter acesso à origem e à morte, uma vez que essa recobre tudo e gera uma confusão entre esses dois termos, razão pela qual a cura passa por uma procura de traços, uma tentativa de pôr em relato uma história que não cessa de escapar para aquele que é fruto dela, ainda que não a tenha vivido. Cabe, a meu ver, ao analista permitir que esses pacientes possam criar uma memória familiar que lhes permita se situar no conjunto e se reconhecer como tendo sido engendrados e serem capazes de engendrar.

É por isso que, alertada por Zaltzman (1999), acredito que o tratamento analítico deve tratar o homem, o ser psíquico, o sujeito, como sujeito da condição humana, como portador de uma realidade psíquica, que é concomitantemente a sua e do conjunto humano que faz dele aquilo que ele é. Ou dito de outra forma, uma análise não diz respeito apenas à determinada organização psicopatológica, ela tem que se haver, quer queira ou não, com o rochedo daquilo que constitui a realidade do humano.

$\mathrm{O}$ analista, ainda que não seja um historiador, não pode, a meu ver, se dar o luxo de ignorar a História, pois como diz Fedida (2007) é seu dever poder imaginar o inimaginável, caso contrário estaria negligenciando que o fato aconteceu. Alguns pacientes nos dizem que o que eles viveram nós teremos imaginar, e estão cobertos de razão. Temos que fazê-lo se quisermos fazer decentemente nosso trabalho. Os horrores vividos por aqueles que tiveram a experiência dos campos, genocídios e ditaduras militares desafiam nossa imaginação, mas nosso trabalho é justamente poder imaginar o horror sem entrar nele, reconhecendo o que ele destrói de nossas próprias representações. Aquele que nos fala do horror precisa saber que há um semelhante que o escuta, o que não é sinônimo de empatia, no sentido de dar a impressão que vivemos o que ele viveu, mas de empatia no sentido que podemos tentar imaginar o que ele viveu, que aceitamos nos prestar a isso.

E para concluir, se o testemunho é um endereçamento que a testemunha dirige a outro que representa a comunidade humana da qual ele foi excluído, aquele que o escuta tem que responder presente, para que sua escuta possibilite àquele que ousou tomar a palavra para falar do irredutível de sua experiência religar os fios de uma vida interrompida por uma catástrofe histórica, visto que ele representa a possibilidade de uma reintegração na comunidade humana.

\section{Between psychoanalysis and history: The testimony}

Abstract: This article approaches the testimonial literature of genocidal survivors to question what they teach the analyst about historical traumas and the effects of historical violence on human subjectivity. The testimonials are here understood as a mix of confession, reflection and historical document, and engage the analyst's responsibility in terms of listening the destruction as well as the resistance to it.

Keywords: trauma, testimony, responsability of the analyst, subjectivity, genocide.

\section{Entre psychanalyse et historie: le témoignage}

Resumé: Cet article se penche sur le témoignage littéraire des survivants des génocides pour se demander ce qu'ils enseignent à l'analyste en ce qui concerne les traumatismes historiques et les effets de la violence historique sur la subjectivité humaine. 
Les témoignages sont ici entendus en tant que mélange de conféssion, réflexion et document historique qui engagent la responsabilité de l'analyste autant dans son écoute de la déstruction que dans la résistance à celle ci.

Mots-clés: traumatisme, témoignage, responsabilité de l'analyste, subjectivité, génocide.

\section{Entre psicoanálisis e historia: el testimonio}

Resumen: Este artículo aborda la literatura testimonial de supervivientes de genocidios para interrogar lo que los supervivientes enseñan al psicoanalista respecto a los traumas históricos y a los efectos de la violencia histórica acerca de la subjetividad humana. Entendemos los testimonios como una mezcla de confesión, reflexión y documento histórico que involucran la responsabilidad del psicoanalista en su escucha tanto acerca de la destrucción como la resistencia al psicoanalista.

Palabras clave: trauma, testimonio, responsabilidad del psicoanalista, subjetividad, genocidio.

\section{Referências}

Abraham, K. (1973). Contributions à la psychanalyse des nevroses de guerre. In Oeuvres Complètes (T. 2). Paris: Payot.

Agamben, G. (1997). Homo sacer. Paris: Seuil.

Agamben, G. (1999). Ce qui reste d'Auschwitz. Paris: Payot. Altounian, J. (2000). La survivance. Paris: Dunod.

Améry, J. (2005). Par-delà le crime et le châtiment. Essaie pour surmonter l'insurmontable. Arles, France: Actes Sud.

Antelme, R. (1947). L'espèce humaine. Paris: Gallimard.

Bubber Newmann, M. (1986). Milena. Paris: Seuil.

Blanchot, M. (1996). Robert Antelme textes inédits sur l'espèce humaine. Essais et témoignage. Paris: Gallimard.

Chalamov, V. (1990). Récits de la Kolyma. Paris: Livre de Poche.

Chiantaretto, J. F. (2004). Témoignage et trauma. Implications psychanalytiques. Paris: Dunod.

Coquio, C. (2003). L'emergence d'une "Littérature" de nonécrivains: les témoignages des catástrofes historiques. Revue d'histoire littéraire de la France, 103, 342-363.

Davoine, F., \& Gaudillère, M. (2006). Histoire et trauma. Paris: Stock.

Delbo, C. (1970). Auschwitz et après. Paris: Les Editions de Minuit.

Fedida, P. (2007). Humain/désumain. Paris: PUF.

Ferenczi, S. (1970). Psychanalyse des nevroses de guerre. In S. Ferenczi, Oeuvres Complètes (T. 2, pp. 27-43). Paris: Payot. (Trabalho original publicado em 1919)

Ferenczi, S. (2003). Elasticidade da técnica psicanalítica. In S. Ferenczi, Psicanálise IV, São Paulo: Martins Fontes. (Trabalho original publicado em 1928)

Freud, S. (1948). Moïse et le monothéisme. Paris: Gallimard. (Trabalho original publicado em 1939)

Freud, S. (1981a). Considerations actuelles sur la guerre et la mort. In Essais de Psychanalyse (pp. 9-40). Paris: Payot. (Trabalho original publicado em 1915)

Freud, S. (1981b). Au delà du principe du plaisir. In Essais de Psychanalyse (pp. 41-115). Paris: Payot. (Trabalho original publicado em 1920)

Kezem, J. (2010). Ferenczi e a Psicanálise contemporânea. Revista Brasileira de Psicanálise, 44(2), 23-28.
Lacan, J. (1968). Proposition du 9 octobre 1967. Scilicet, 1, 14-30.

Levallois, A. (2007). Une psychanalyste dans l'histoire. Paris: Campagne Première.

Levi, P. (1987). Si c'est um homme. Paris: Julliard.

Levi, P. (1989). Les naufragés et les rescapés. Paris: Gallimard.

Levi, P. (1997). A trégua. São Paulo, SP: Cia. das Letras.

Oppenheim, D. (2012). Peut-on guérir de la Barbarie? Paris: Desclée de Brouwer.

Piret, B. (2013). Approche psychanalytique du traumatisme. Recuperado de www.parole-sans-frontiere.org/spip. php?article297

Prado Oliveira, L. R. (2012). O sentido da amizade em Ferenczi: uma contribuição à clínica psicanalítica. Rio de Janeiro, RJ: Uapê.

Revault D'Allones, M. (1999). Ce que l'homme fait à l'homme. Essaie sur le mal politique. Paris: Flammarion.

Seligmann, M.(2000). A história como trauma. In A. Nestrovski. M. Seligmann-Silva (Orgs.), Catástrofe $e$ Representação (pp. 73- 98). São Paulo: Escuta.

Semprum, J. (1994). L'écriture ou la Vie. Paris: Gallimard.

Semprum, J., \& Wiesel, E. (1995). Se taire est impossible. Paris: Milles et une Nuits.

Stewart, S. (2009). Mémoire de l'inhumain: du trauma à la créativité. Paris: Campagne Première.

Waintrater, R. (2005). Dès lumières à l'obscurité: Robert Antelme et Jean Améry, deux itinéraires. Topique, 3(92), 95-110.

Zaltzman, N. (1998). De la guérison psychanalytique. Paris: PUF.

Zaltzman, N. (1999). La résistance de l'humain. Paris: PUF. 